\title{
Electron Induced Dissociation of Singly Deprotonated Peptides
}

\author{
Anastasia Kalli, ${ }^{1,3}$ Gabriela Grigorean, ${ }^{1,2}$ Kristina Håkansson ${ }^{1}$ \\ ${ }^{1}$ Department of Chemistry, University of Michigan, 930 North University Avenue, Ann Arbor, MI 48109-1055, USA \\ ${ }^{2}$ Current Address: MS Proteomics at The European Institute of Oncology, via Adamello 16, 20139 Milan, Italy \\ ${ }^{3}$ Current Address: Proteome Exploration Laboratory, Division of Biology, California Institute of Technology, Pasadena, CA \\ 91125, USA
}

\begin{abstract}
Dissociation of singly charged species is more challenging compared with that of multiply charged precursor ions because singly charged ions are generally more stable. In collision activated dissociation (CAD), singly charged ions also gain less kinetic energy in a fixed electric field compared with multiply charged species. Furthermore, ion-electron and ion-ion reactions that frequently provide complementary and more extensive fragmentation compared with CAD typically require multiply charged precursor ions. Here, we investigate electron induced dissociation (EID) of singly deprotonated peptides and compare the EID fragmentation patterns with those observed in negative ion mode CAD. Fragmentation induced upon electron irradiation and collisional activation is not specific and results in the formation of a wide range of product ions, including $b-, y$-, $a$-, $x$-, $c$-, and $z$-type ions. Characteristic amino acid side chain losses are detected in both techniques. However, differences are also observed between EID and CAD spectra of the same species, including formation of odd-electron species not seen in CAD, in EID. Furthermore, EID frequently results in more extensive fragmentation compared with CAD. For modified peptides, EID resulted in retention of sulfonation and phosphorylation, allowing localization of the modification site. The observed differences are likely due to both vibrational and electronic excitation in EID, whereas only the former process occurs in CAD.
\end{abstract}

Key words: Electron induced dissociation, Collision activated dissociation, Singly charged peptide anions

\section{Introduction}

$\mathrm{T}$ he dissociation of peptides in tandem mass spectrometry (MS/MS) is a widely used technique for obtaining sequence information, with the vast majority of tandem mass spectrometric techniques utilizing positive ion mode and frequently relying on fragmentation of doubly protonated

Electronic supplementary material The online version of this article (doi:10.1007/s13361-011-0233-6) contains supplementary material, which is available to authorized users.

Correspondence to: Kristina Håkansson; e-mail: kicki@umich.edu species generated by electrospray ionization (ESI) [1]. Biomolecules can also be introduced into the gas phase by matrix-assisted laser desorption/ionization (MALDI) [2, 3], which is more tolerant to salts and impurities, and shows less ion suppression compared with ESI. However, because MALDI produces predominantly singly charged ions, generation of informative tandem mass spectra is more challenging compared with the dissociation of multiply charged precursor ions [4-7]. Specifically, low-energy collision activated dissociation (CAD) MS/MS of singly protonated peptides containing lysine and arginine often results in highly selective bond cleavages and poor sequence coverage, [8-11] presumably due to the absence of a mobile proton that can promote backbone bond cleavages $[8-10,12]$. 
To overcome this limitation, Lebrilla and co-workers employed a combination of infrared and collisional activation (CIRCA) to access higher energy fragmentation pathways $[9,10]$. These authors demonstrated that for singly protonated model and tryptic peptides, CIRCA provided greater sequence coverage and higher quality spectra compared with $\mathrm{CAD}$ or infrared multiphoton dissociation (IRMPD) alone. In a different approach, Reilly and coworkers have shown that $157 \mathrm{~nm}$ photodissociation of singly protonated peptides produces informative spectra from which structural information can be obtained $[13,14]$. The fragmentation pathways observed in $157 \mathrm{~nm}$ photodissociation are different compared with those observed in vibrational excitation of precursor ions: $x$-, $v$-, and $w$-type product ions were observed when the charge was localized at the Cterminus, whereas $a$ - and $d$-type product ions were detected when the charge was localized at the N-terminus [13]. Photodissociation at $193 \mathrm{~nm}$ has also been exploited for fragmentation of singly protonated peptides [15-18]. Similar to $157 \mathrm{~nm}$ dissociation, formation of $a$ - and $d$-type product ions was observed when arginine residues were in close proximity to the $\mathrm{N}$-terminus and $y$-, $x$ -,$v$ - and $w$-type fragments were detected when Arg residues were located near the C-terminus [17, 19]. Detailed investigations of $193 \mathrm{~nm}$ photodissociation revealed that the fragmentation behavior is significantly affected by the presence and location of arginine residues [16], and that product ion types and abundances vary depending on precursor ion charge location [20].

All the aforementioned work focuses on fragmentation of singly protonated peptides, i.e., positive ion mode MS/MS. However, utilization of negative ion mode is often desired, given that $\sim 50 \%$ of naturally occurring proteins are acidic. Peptides containing numerous acidic residues (e.g., glutamic and aspartic acid) may be challenging to detect in positive ion mode [21-23]. On the other hand, it has been shown that highly basic peptides can easily form singly deprotonated ions with sufficient intensities for fragmentation experiments [24]. Furthermore, negative ion mode provides enhanced sensitivity for peptides containing acidic post-translational modifications such as sulfonation [25] and phosphorylation [26].

Cassady and co-workers have examined the dissociation of singly charged basic and acidic peptides in positive and negative ion mode post source decay (PSD) and showed that negative ion PSD results in structurally informative spectra, complementary to those obtained in positive ion mode [22, 24]. The main product ion types in negative ion mode PSD correspond to $y$-, $b$-, and $c$-type ions. Bowie and co-workers have examined extensively the dissociation of singly deprotonated peptides in negative ion mode CAD and demonstrated that sequence information can be derived $[27,28]$. For example, comparison of positive and negative ion mode CAD of singly charged bioactive peptides containing four to five amino acids showed that negative ion spectra were as informative or at least complementary to the positive ion spectra [28]. Harrison has shown that low- energy CAD of singly deprotonated peptides resulted in sufficient fragmentation to establish the amino acid sequence of di- to pentapeptides containing $\mathrm{H}$ or alkyl side chains and he concluded that negative ion mode CAD provided as much information as positive ion mode CAD of protonated peptides [29]. However, one drawback of negative ion mode peptide PSD and CAD is extensive neutral and side chain loss, and the formation of internal product ions. Neutral losses do not provide sequence information and the diverse fragmentation processes yield complex spectra, thereby reducing MS/MS sensitivity and rendering spectral interpretation more difficult.

Electron capture dissociation (ECD) [30] and electron transfer dissociation (ETD) [31] have been shown to be complementary and result in more extensive fragmentation compared with slow heating techniques such as CAD [3234]. However, ECD and ETD are only applicable to positively charged precursor ions carrying at least two charges. Electron detachment dissociation (EDD) [35, 36] involves dissociation of multiply charged anions and results in the formation of $a$ - and $x$-type product ions. A major advantage of EDD compared with slow heating techniques is the retention of phosphorylation [37] and sulfonation [35]. Similar fragmentation pathways, i.e., formation of $a$ - and $x$ type product ions, was observed in negative electron transfer dissociation (NETD) [38, 39], although phosphate loss was prevalent when xenon was used as reagent $[38,39]$. EDD and NETD spectra are less complex compared with those obtained from PSD and CAD because neutral and side chain losses are significantly less prevalent. However, both EDD and NETD require at least doubly negatively charged precursor ions, limiting their applicability for singly charged species.

Ion-electron reactions of singly charged cations were previously examined for small organic molecules [40-42]. For such cationic species, interaction with electrons in the energy range $2-70 \mathrm{eV}$, produced by a continuous electron beam, resulted in excitation followed by fragmentation similar to that obtained in CAD. This technique was originally termed electron impact excitation of ions from organics (EIEIO) [41, 42] and later termed electron induced dissociation (EID) [40], which is the term we use here. Wang and McLafferty performed $70 \mathrm{eV}$ EID of sodium cationized, $[\mathrm{M}+\mathrm{Na}]^{+}$, precursor ions from the cyclic peptide gramicidin S [43]. Similar to the case of small organic molecules, the fragmentation observed in EID was similar to that in CAD.

More recently, O'Hair and co-workers explored EID of singly protonated aromatic amino acids, cystine, and small peptides. These authors showed that EID yielded different and complementary fragmentation compared with CAD and suggested that ion activation in EID proceeds via both electronic and vibrational excitation [44]. Julian and coworkers extended this work to larger protonated peptides and reported that several fragmentation pathways observed in EID of singly charged peptide cations are radical-induced 
[45]. Furthermore, the fragmentation of singly protonated and sodiated betaine dimers in EID was examined by O'Hair and co-workers who reported that betaine loss was the dominant fragmentation pathway for both the protonated and sodiated species [46]. Zubarev and co-workers performed EID of protonated and sodiated oligosaccharides and showed that full sequence coverage could be obtained, similar to CAD of the same species, and to ECD of the corresponding doubly protonated species [47]. EID has also recently been applied for structural elucidation of singly charged ions of oxo-centred trinuclear carboxylate-bridged iron complexes [48], octaethylporphyin and its iron(II) complex [49], and small organic cationic molecules [50]. In a different approach, Zubarev and co-workers recently demonstrated that irradiation of molecular cations with higher energy electrons $(>20 \mathrm{eV})$ can cause double ionization followed by subsequent fragmentation to produce extensive backbone dissociation. This fragmentation technique has been termed electron ionization dissociation [51] (also abbreviated EID) and is different from electron induced dissociation, which is utilized here.

In contrast to EID of singly cationized species, very few reports focused on negative ion mode EID. Yoo and Hakansson applied negative ion mode EID to phosphate-containing metabolites and showed that EID results in complementary fragmentation compared with CAD and IRMPD [52]. In addition, Amster and co-workers applied EID to singly charged anions from sulfonated glycosaminoglycans [53]. These authors showed that EID resulted in fragmentation similar to that observed in EDD, but different from that observed in CAD and IRMPD of the same molecule. Both odd- and even-electron product ions were observed in EID [53]. More recently, EID of doubly deprotonated tryptophan clusters was investigated [54] and it was shown that EID proceeds via different pathways depending on the electron energy. In agreement with previous reports [52,53], the complementarity of EID and CAD was also demonstrated [54].

Here, we examine the applicability of EID for the dissociation and characterization of singly deprotonated peptides and compare the fragmentation patterns with those observed in negative ion mode CAD. These experiments aimed to examine the fragmentation pathways in EID of peptide anions and also to address whether EID provides complementary information compared with CAD for peptide analysis.

\section{Experimental}

\section{Sample Preparation}

The peptides H-RPKPQQFFGLM-NH $\mathrm{H}_{2}, \mathrm{H}-$ RPKPQQFFGLM-OH, $\mathrm{CH}_{3} \mathrm{CO}-\mathrm{RRA}(\mathrm{pS}) \mathrm{VA}-\mathrm{OH}$ (phosphorylated at serine), H-WHWLQL-OH, pEHWSYGLRPG$\mathrm{NH}_{2}$, pEHWSYGLRPG-OH, H-PPGFSPFR-OH, pEQWFWWM-NH ${ }_{2}$, pEVNFSPGWGT-NH2, and HGNLWATGHFM-NH $\mathrm{N}_{2}$ were purchased from Sigma (St. Louis, MO, USA) and the peptides H-DY*MGWMDF- $\mathrm{NH}_{2}$ (sulfonated at tyrosine) and H-DYMGWMDF- $\mathrm{NH}_{2}$ were obtained from Advanced Chemtech (Louisville, KY, USA) and used without further purification. H-WHWLQL-OH was diluted to a final concentration of $1 \mu \mathrm{M}, \mathrm{CH}_{3} \mathrm{CO}-\mathrm{RRA}(\mathrm{pS}) \mathrm{VA}-$ $\mathrm{OH}$ to $1.7 \mu \mathrm{M}$, and H-PPGFSPFR-OH to $3 \mu \mathrm{M}$. All other peptides were diluted to $5 \mu \mathrm{M}$. All peptides, except $\mathrm{H}$ WHWLQL-OH, were electrosprayed from a spraying solvent containing 1:1 isopropanol:water (Fisher Scientific, Fair Lawn, NJ, USA) and $10 \mathrm{mM}$ ammonium acetate (Fisher Scientific). For H-WHWLQL-OH, $0.4 \%$ piperidine (Acros Organics, Morris Plains, NJ) was used instead of $10 \mathrm{mM}$ ammonium acetate.

\section{Mass Spectrometry}

All experiments were performed with an actively shielded $7 \mathrm{~T}$ quadrupole Fourier transform ion cyclotron resonance (Q-FT-ICR) mass spectrometer (Apex-Q; Bruker Daltonics, Billerica, MA, USA), which has been previously described [55]. The peptides were electrosprayed in negative ion mode at a flow rate of $70 \mu \mathrm{L} / \mathrm{h}$. Ions were accumulated in the first hexapole for $0.1 \mathrm{~s}$, transferred through the mass selective quadrupole $(10 \mathrm{~m} / \mathrm{z}$ isolation window), mass selectively accumulated in the second hexapole for 0.1 to $3 \mathrm{~s}$ to optimize ion abundances for MS/MS experiments, transferred through high-voltage ion optics, and captured in the ICR cell by dynamic trapping. This accumulation sequence was looped twice. EID was performed with an indirectly heated hollow dispenser cathode at a bias voltage of $10-12 \mathrm{~V}$ and an irradiation time of 5,8 , or $10 \mathrm{~s}$. A lens electrode located in front of the hollow cathode was kept $0.3-1.0 \mathrm{~V}$ lower than the cathode bias voltage. CAD was performed in the hexapole collision cell with argon as collision gas.

All spectra were acquired with XMASS (ver. 6.1; Bruker Daltonics) using 256 or $512 \mathrm{~K}$ data points and summed over 32 (for CAD experiments) or 64 (for EID experiments) scans. Data processing was performed with the MIDAS [56] analysis software. Internal frequency-to-mass calibration was performed by Microsoft Excel with a two-term calibration equation. The calculated masses of the precursor ions and abundant product ions were used for calibration. The product ions used for calibration are indicated in Tables S1A to S12B in Supplemental Data. Product ion spectra were interpreted using the MS Product function (http:// prospector.ucsf.edu/prospector/cgi-bin/msform.cgi?for $\mathrm{m}=$ msproduct) in Protein Prospector. Only peak assignments with a mass accuracy better than $15 \mathrm{ppm}$ were accepted.

\section{Results and Discussion}

\section{EID and CAD of Singly Deprotonated Amidated and Free Acid Forms of Substance P}

EID of singly deprotonated Substance P, HRPKPQQFFGLM-NH ${ }_{2}$, is shown in Figure 1a. CAD of the same species was performed for comparison (Figure 1b). All 

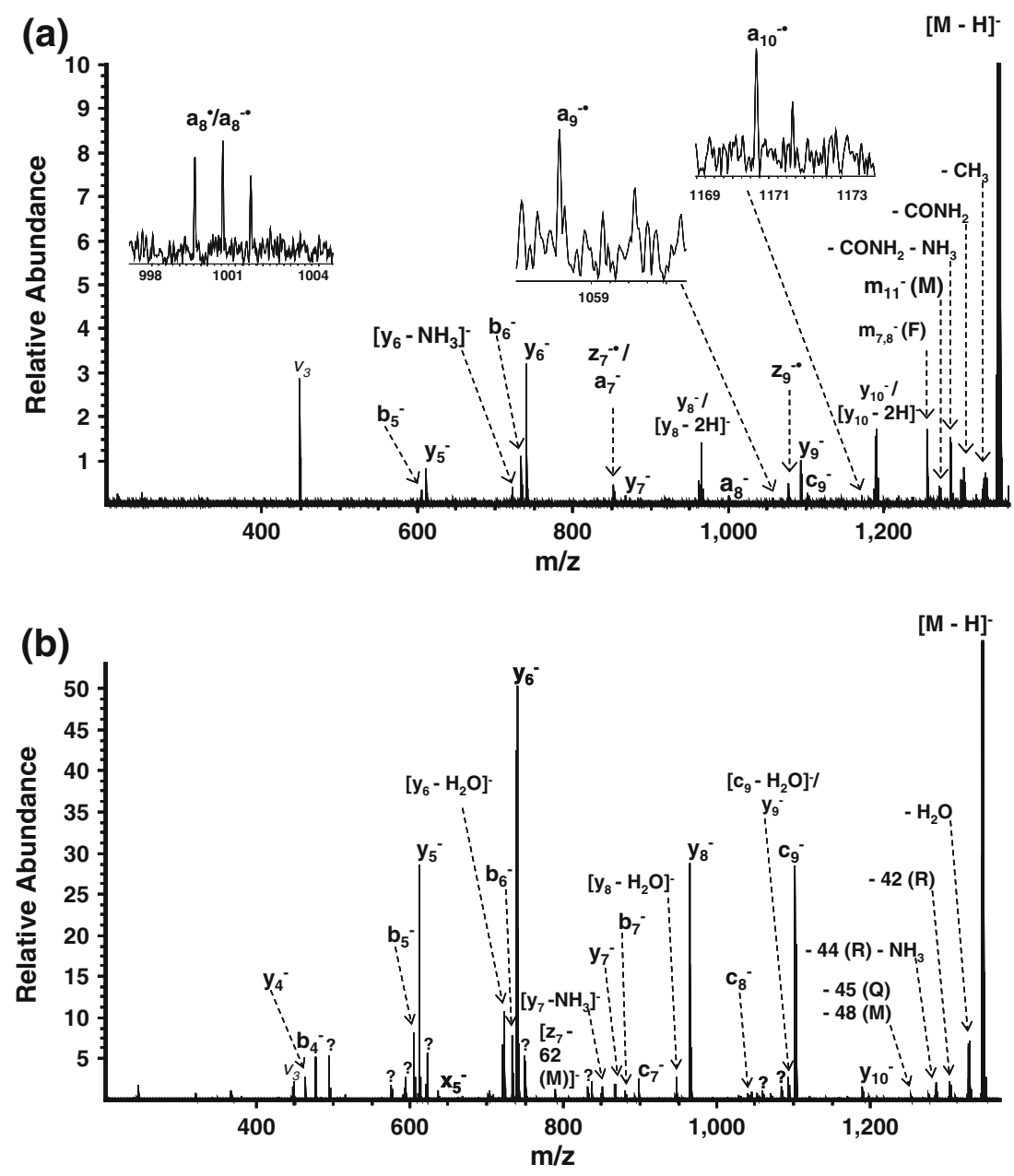

Figure 1. EID (a) and CAD (b) spectra of the singly deprotonated amidated form of Substance P (H-RPKPQQFFGLM-NH $\left.{ }_{2}\right)$. Following both electron irradiation and collisional activation, $b$ - and $y$-type product ions are observed. However, in EID, several radical species are detected. By contrast, no odd-electron species are formed in CAD. Characteristic side chain losses from phenylalanine and methionine are detected in EID. Several product ions in the CAD spectrum could not be assigned based on known fragmentation pathways. ? = unidentified product ions, $v_{3}=3^{\text {rd }}$ harmonic

assigned product ions are summarized in Supplemental Data, Tables S1A and S1B. EID of the Substance P anions resulted in formation of several $b$ - and $y$-type product ions, which dominate in slow heating techniques such as CAD and IRMPD. However, for this peptide, several odd-electron species, $z_{7}{ }^{\circ}, z_{9}, a_{9}{ }^{\cdot}$, and $a_{10}{ }^{\bullet}$ were also detected. Formation of a-type radical ions has also been observed in CAD of radical anions formed by UV photodetachment of electrons from doubly deprotonated peptides [57]. The $a_{8}$ product ion was a mixture of odd- and even-electron species (see inset, Figure 1a). These radical ions were unique to EID (absent following $\mathrm{CAD}$ ). Formation of odd-electron product ions from even-electron precursor ions, although not common, has been previously observed in EID of glycosaminoglycan anions and it was suggested that these odd-electron products arise from electronic excitation of the even-electron precursor ions [53]. Alternatively, irradiation of molecular ions with high energy electrons may result in hydrogen atom ejection followed by subsequent fragmentation to produce odd-electron $z^{\circ}$ - and $a^{\circ}$-type product ions. In EID, the $y$-type product ions corresponding to cleavages at the N-terminal side of proline were observed as $y_{8}$ and $\left[y_{8}-2 \mathrm{H}\right]$ and $y_{10}$ and $\left[y_{10}-2 \mathrm{H}\right]$. These hydrogen deficient species were not observed in CAD. Side chain losses from phenylalanine $\left(\mathrm{PhCH}_{2}, 91.055 \mathrm{Da}\right)$ and methionine $\left(\mathrm{CH}_{2} \mathrm{CH}_{2} \mathrm{SMe}\right.$, $75.027 \mathrm{Da})$ were only detected following EID. Such side chain losses have been previously reported in CAD of singly deprotonated dipeptides formed by fast atom bombardment (FAB) [58, 59]; however they were absent in our low energy CAD of Substance $\mathrm{P}-\mathrm{NH}_{2}$ (Figure 1b). CAD of C-terminally amidated Substance $\mathrm{P}$ anions resulted in the formation of mainly $b$ - and $y$-type product ions although some $c$-type products, $c_{7}, c_{8}$, and $c_{9}$, were also detected. In EID, only the $c_{9}$ product ion was observed. Formation of $c$-type product ions is generally observed in negative ion mode CAD [21, $29,60]$. Some $y$ - and $b$-type ions, $y_{4}, b_{4}$, and $b_{7}$, observed in CAD were absent in EID. Interestingly, several CAD product ions could not be identified based on known 
fragmentation pathways ( $a$ -,$b-, c-, x-, y$-, and $z$-type product ions, $\mathrm{NH}_{3}$ and $\mathrm{H}_{2} \mathrm{O}$ losses from precursor and product ions, and amino acid side chain losses from precursor and product ions). In contrast, EID resulted in less complex spectra in which all product ions were identified.

EID and CAD of the singly deprotonated free acid form of Substance P, H-RPKPQQFFGLM-OH, are displayed in Figure $2 \mathrm{a}$ and $\mathrm{b}$ (complete list of all assigned product ions are shown in Supplemental Data, Tables S2A and S2B). Similar to EID and CAD of the singly deprotonated amidated form, extensive $b$ - and $y$-type product ions are formed. For this peptide, only one radical species, $\mathrm{z}_{9}{ }^{\circ}$, was detected in EID. Some $a$-type product ions, $a_{8}, a_{9}, a_{10}$, are also observed; however they are even-electron species whereas, in EID of amidated Substance P, the $a$-type products were detected as odd-electron species. These product ions, $\mathrm{z}_{9}^{\cdot}, a_{8}, a_{9}$, and $a_{10}$, were absent in the CAD spectrum. Also, the product ions $x_{4}, x_{5}$, and $y_{3}$ were present only in the EID spectrum. As observed for the amidated form of Substance P, $y$-type product ions, $y_{8}$ and $y_{10}$, corresponding to cleavage at the $\mathrm{N}$-terminal side of proline were detected as both $y_{\mathrm{n}}$ and $\left[y_{\mathrm{n}}-2 \mathrm{H}\right]$-type species. These hydrogen deficient species were not observed following $\mathrm{CAD}$, whereas the $c_{5}, c_{6}, c_{8}$, and $b_{8}$ product ions were only detected following CAD. For both the amidated and free acid form of Substance P, several product ions were unique in the EID or CAD spectra, suggesting that EID and CAD can provide complementary structural information.

The differences observed between the EID spectra of the amidated and free acid singly deprotonated forms of Substance P, and also between the CAD spectra of these two singly deprotonated forms, suggest that charge location can affect fragmentation patterns in both EID and CAD. For example, side chains losses from arginine (100.087 Da), leucine (57.070 Da), glutamine (72.045 Da), and methionine $(62.019 \mathrm{Da})$, and $x$-type product ions were only detected in
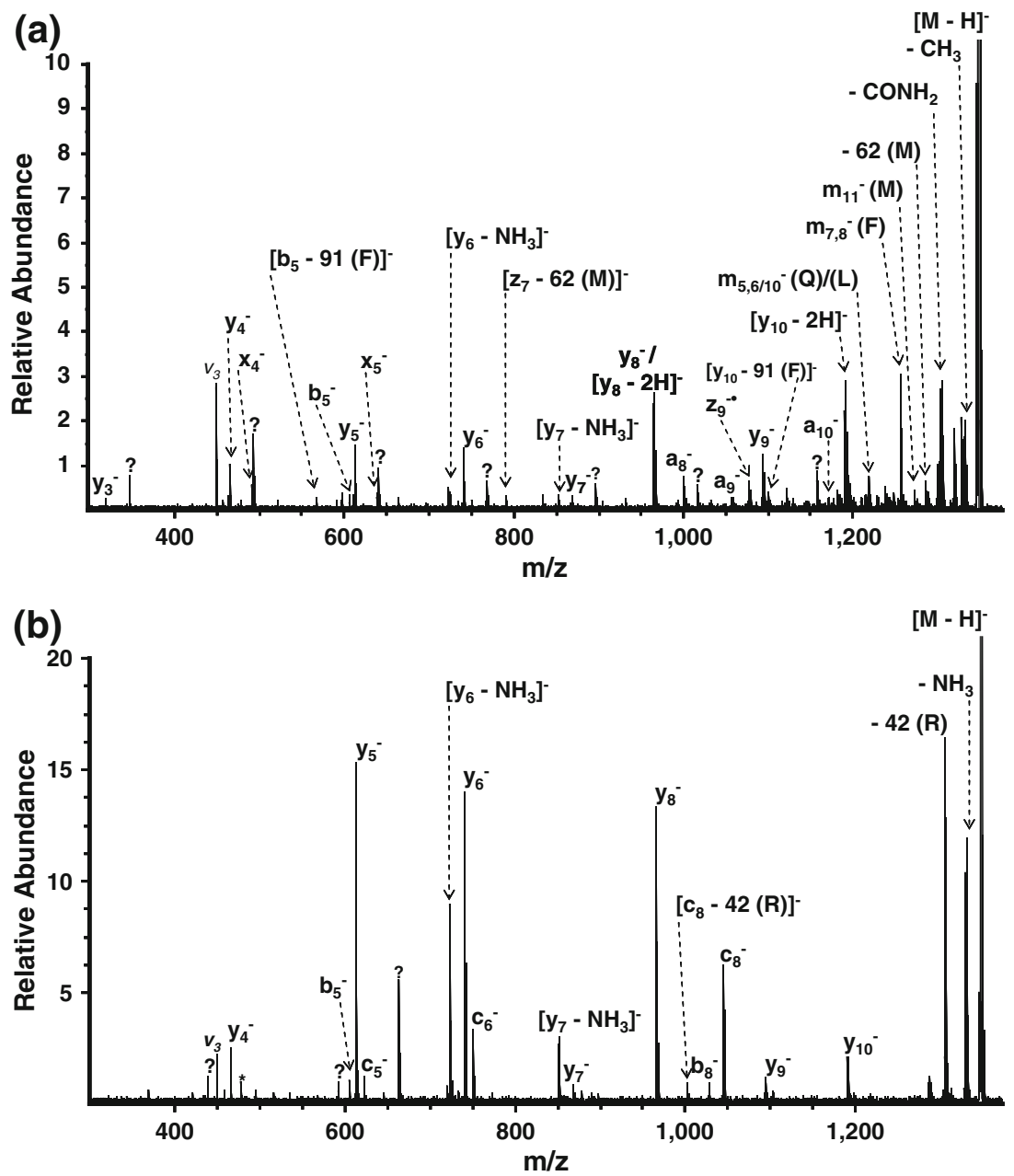

Figure 2. EID (a) and CAD (b) spectra of the singly deprotonated free acid form of Substance P (H-RPKPQQFFGLM-OH). EID resulted in more extensive fragmentation compared with CAD. $a$ - and $x$-type product ions were solely formed in EID. Characteristic side chain losses from the precursor and product ions are dominant in EID. Some product ions formed in EID could not be assigned based on known fragmentation pathways. Only the major peaks are labeled in the figure, complete lists of all observed product ions are given in Supplemental Data, Tables S2A and S2B. ? =unidentified product ions, *=noise peak, $v_{3}=3^{\text {rd }}$ harmonic 
EID of the free acid form. Also, the $y_{3}$ and $y_{4}$ product ions were only present in EID of the free acid form whereas the $b_{6}, a_{7}$, and $c_{9}$ product ions were only detected for the amidated form. Several product ions in the EID spectrum of the free acid form could not be assigned based on known fragmentation pathways (as defined above) whereas, in EID of the amidated form, all product ions were assigned. Differences in fragmentation patterns between the amidated and free acid form of Substance P were also reported by Tsybin et al. in ECD of doubly protonated species: ECD of the free acid form resulted in formation of several $a$ - and ytype product ions, not detected following ECD of the amidated form [61]. These authors suggested that charge location affects the ECD outcome [61]. Differences observed in negative ion mode CAD (Figures $1 \mathrm{~b}$ and $2 \mathrm{~b}$ ) of the two forms of Substance $\mathrm{P}$ include the product ions $b_{4}, b_{7}, c_{7}, z_{7}$, $x_{5}$, and $c_{9}$, only detected for the amidated form whereas the product ions $c_{5}, c_{6}, c_{8}$, and $b_{8}$ were present only in CAD of the free acid form. Furthermore, the free acid form produced a less complex spectrum compared with that of the amidated form. For the free acid form, the C-terminal carboxylic acid is likely the deprotonation site whereas, for the amidated form, the charge location is less predictable because no acidic groups are present. It has been suggested that backbone amide hydrogens are the next most acidic hydrogens after the hydrogen atoms of carboxylate groups [36]. Therefore, for the amidated form of Substance P, possible deprotonation sites include any of the backbone amide hydrogens. Regardless of the exact position of the deprotonation site, it appears that charge location influences the fragmentation outcome in both EID and CAD of singly deprotonated species.

\section{EID and CAD of Singly Deprotonated Amidated and Free Acid Forms of LHRH}

EID and CAD of the singly deprotonated amidated form of luteinizing hormone releasing hormone (LHRH, pEHWSYGLRPG- $\mathrm{NH}_{2}$ ) showed relatively similar fragmentation, including formation of mainly $b$ - and $y$-type product ions (Supplemental Data, Tables S3A and S3B). Products corresponding to loss of $\mathrm{HCHO}(30.011 \mathrm{Da})$ from the serine residue were present in both spectra, although this loss was more dominant in the CAD spectrum. Characteristic side chain loss from serine- (formaldehyde, HCHO) and threonine- (acetaldehyde, $\mathrm{CH}_{3} \mathrm{CHO}$ ) containing peptides have previously been reported in negative ion mode $\mathrm{CAD}[27,60,62,63]$.

Neutral loss from tryptophan side chains was observed in both CAD and EID of singly deprotonated LHRH-NH $\mathrm{N}_{2}$. In CAD, loss of $129 \mathrm{Da}\left(\mathrm{C}_{9} \mathrm{H}_{7} \mathrm{~N}, 129.058 \mathrm{Da}\right)$ was seen whereas, in EID, loss of $130 \mathrm{Da}\left(\mathrm{C}_{9} \mathrm{H}_{8} \mathrm{~N}, 130.066 \mathrm{Da}\right)$ was observed. In agreement with our results, loss of $129 \mathrm{Da}$ from Trp residues has been previously observed in CAD of singly deprotonated peptides formed by FAB and was proposed to result from charge migration (producing a deprotonated $\mathrm{N}$ terminus) followed by formation of an indole anion and hydride transfer [59]. This loss was also reported in EID of singly protonated amino acids [44]. In ECD, loss of $131 \mathrm{Da}$ $\left(\mathrm{C}_{9} \mathrm{H}_{9} \mathrm{~N}, 131.074 \mathrm{Da}\right)$ from Trp residues has been reported [64] and we have documented loss of $129 \mathrm{Da}$ from the Trp side chain in EDD [65].

A major difference between CAD and EID of singly deprotonated LHRH-NH $\mathrm{H}_{2}$ is the detection of two radical species, $a_{8}{ }^{\bullet}$ and $a_{9}{ }^{\circ}$, in EID, similar to EID of Substance P-NH $\mathrm{N}_{2}$. The $\left[y_{9}-\mathrm{NH}_{3}\right]$ product ion was only detected in EID whereas the $c_{3}$ and $b_{8}$ product ions were only observed in CAD.

The free acid form of LHRH was also investigated (Supplemental Data, Tables S4A and S4B). For this peptide, no odd-electron products were detected in EID of the singly deprotonated species. Some $a$-type ions, $a_{7}$ and $a_{8}$, were formed but they were detected as even-electron species, similar to EID of the free acid form of Substance P. These product ions were absent in CAD. Also, the $c_{5}$ product ion was present only in the EID spectrum. Some $b$ - and $y$-type product ions, $y_{8}, y_{5}$, and $b_{7}$, were only formed in CAD. Side chain losses and $\mathrm{H}_{2} \mathrm{O}$ and $\mathrm{NH}_{3}$ losses from both the precursor and product ions were significantly more pronounced in CAD compared with EID (Supplemental Data, Tables S4A and S4B). The observed differences between CAD and EID spectra of LHRH suggest that these two fragmentation techniques proceed via different activation pathways.

Similar to EID of the amidated and free acid forms of Substance P, differences are observed between the EID spectra of the amidated and free acid forms of LHRH. For example, formation of odd-electron species was not observed for the free acid form. Furthermore, the $y_{6}, c_{5}$, and $a_{7}$ product ions were only detected for the free acid form whereas the $y_{8}$ product ion was only observed for the amidated form. Similar trends were apparent in CAD spectra, in which some product ions were only observed for the amidated or free acid form, respectively. Neutral losses from the precursor and product ions were more abundant in CAD of the free acid form. Therefore, as discussed above, the charge location appears to influence the fragmentation outcome in both EID and CAD. Differences in fragmentation behavior were also reported in ECD of the amidated and free acid forms of LHRH [61]. For example, for the free acid form, several $y$-type product ions were detected, which were not observed in ECD of the amidated form.

\section{EID and CAD of Other Singly Deprotonated C-terminally Amidated Peptides without Acidic Sites}

Because C-terminally amidated Substance P and LHRH (neither of which contains acidic sites) yielded more radical (unique) product ions in EID compared with their free acid forms, we proceeded to characterize EID of other Cterminally amidated peptides without acidic sites. Product ions observed in EID and CAD of singly deprotonated neuromedin B, H-GNLWATGHFM- $\mathrm{NH}_{2}$, are listed in Supplemental Data, Tables S5A and S5B. The precursor ions and the majority of product ions exhibited abundant 
neutral loss of $\mathrm{CH}_{3} \mathrm{CHO}$ (44.026 Da) from the threonine residue. $y$-type product ions were detected in both CAD and EID. The $y_{7}$ product ion was observed only in EID whereas the $c_{8}$ product ion was only present in CAD. Furthermore, for this peptide, side chain loss from tryptophan was only detected in EID. By contrast, in the case of LHRH, side chain loss from tryptophan was present in both CAD and EID. Two radical species, $z_{6}{ }^{\circ}$ and $a_{9}{ }^{\circ}$, were only formed in EID, although the $a_{9}{ }^{\cdot}$ product ion was detected with low abundance. As discussed above, formation of radical species in EID can be due to electronic excitation of molecular ions, or due to hydrogen atom ejection followed by radical-driven fragmentation. Similar to CAD of Substance $\mathrm{P}-\mathrm{NH}_{2}$, several product ions detected in CAD of neuromedin $\mathrm{B}$ could not be assigned based on known fragmentation pathways.

EID of the singly deprotonated peptide pEVNFSPGWGT$\mathrm{NH}_{2}$ resulted in several product ions not detected in CAD, including $a_{9}{ }^{\circ}, c_{7},\left[b_{7}-\mathrm{H}\right]^{\circ}$, $\left[b_{6}-30\right]$ (serine side chain loss), $a_{5}$ and $c_{4}$ (Supplemental Data, Tables S6A and S6B). In CAD, only two product ions corresponding to backbone bond cleavages were observed, $y_{7}$ and $y_{8}$. Similar to the previously examined peptides containing Ser or Thr residues, characteristic $\mathrm{HCHO}(30.0106 \mathrm{Da})$ and $\mathrm{CH}_{3} \mathrm{CHO}(44.026 \mathrm{Da})$ losses were highly abundant in CAD and EID spectra of pEVNFSPGWGT-NH $\mathrm{H}_{2}$. The EID spectrum of pEVNFSPGWGT-NH $\mathrm{N}_{2}$ was more informative compared with CAD because it contained more backbone product ions.

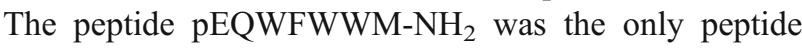
examined here for which EID (Supplemental Data, Table S7A) resulted in less extensive fragmentation compared with CAD (Supplemental Data, Table S7B). Four product ions, $y_{3},\left[z_{4}-75\right],\left[x_{5}-62\right]$, and $\left[z_{6}-130\right]$, detected in CAD, were absent in the EID spectrum. Several neutral losses (see Supplemental Data, Tables S7A and S7B) are observed in the CAD and EID spectra.

We have previously examined EDD of the doubly depro-

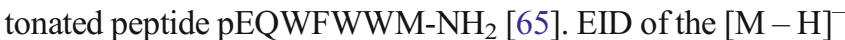
precursor ions from this peptide (Table S7A, Supplemental
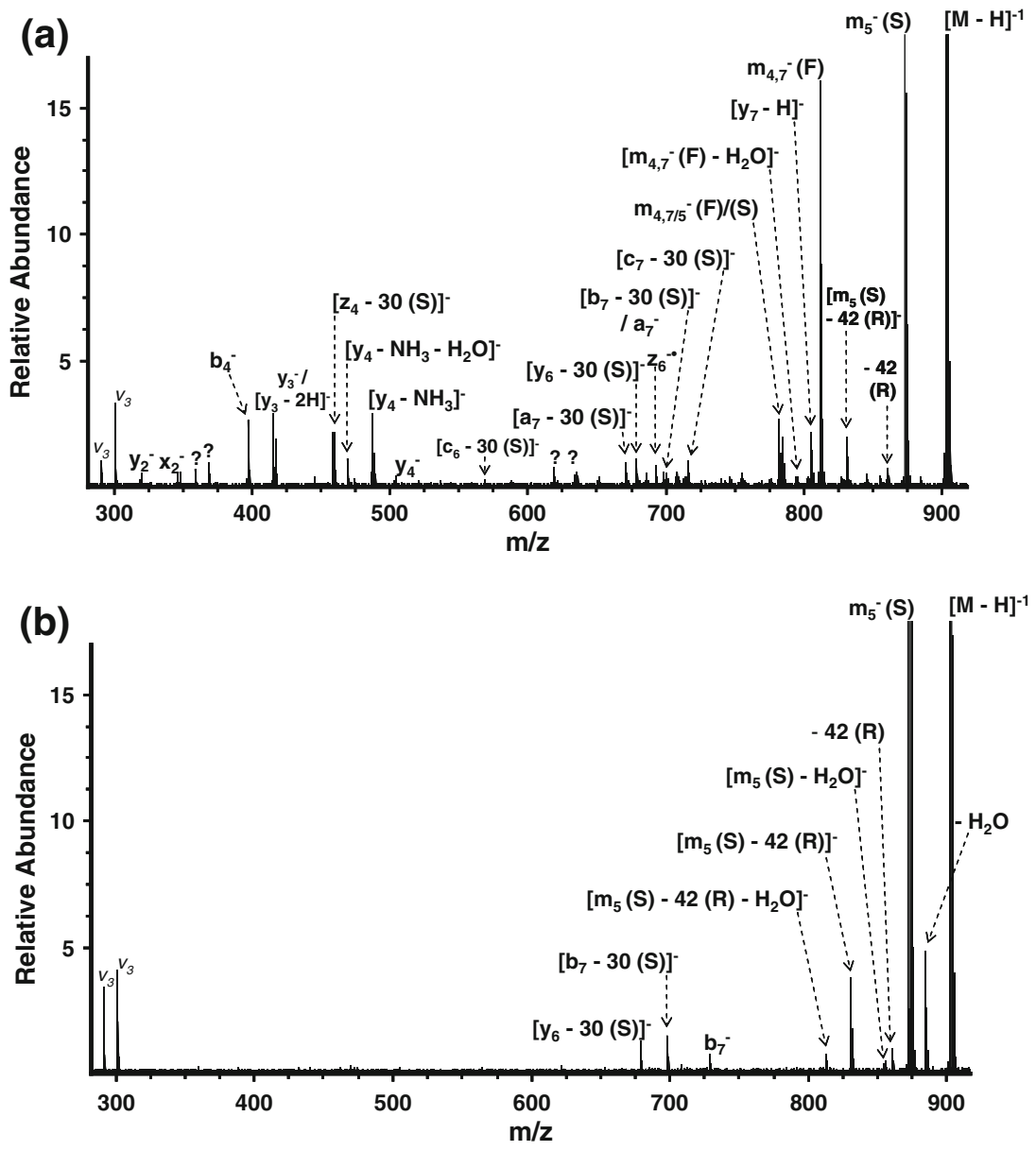

Figure 3. EID (a) and CAD (b) spectra of singly deprotonated bradykinin (H-PPGFSPFR-OH). EID resulted in a highly informative spectrum: a series of $b$ - and $y$-type product ions is observed, and $a-, x$-, and $z$-type product ions are also detected. Product ions corresponding to loss of serine and phenylalanine side chains are also present. In CAD, few sequence specific product ions were formed. Instead, side chain and small molecule neutral losses are mainly observed. Only the major peaks are labeled in the figure, complete lists of all observed product ions are given in Supplemental Data, Tables S8A and S8B. ?= unidentified product ions, $v_{3}=3^{\text {rd }}$ harmonic 
Data) showed similar fragmentation as EDD of the $[\mathrm{M}-2 \mathrm{H}]^{2-}$ precursor ions; however, some differences between these spectra were also observed. For example, formation of $c$ - and $x$-type product ions was observed in both techniques whereas formation of $y$-type product ions was detected only in EID. Neutral loss of the tryptophan side chain and neutral loss of the amidated C-terminus were present in both spectra; however, these losses were more predominant in EDD spectra. The higher yield of Trp side chain loss observed in EDD can be due to the low vertical ionization energy of Trp, which may allow direct electron detachment from Trp and, therefore, steer the fragmentation in EDD [65]. By contrast, EID of singly deprotonated species is unlikely to occur via electron detachment because this would result in neutralization of the precursor and product ions.

In our previous work [65], we also performed EDD of the peptides pEVNFSPGWGT-NH ${ }_{2}$ and H-GNLWATGHFM$\mathrm{NH}_{2}$. For these two peptides, only one backbone product ion was observed and, instead, neutral loss corresponding to cleavage of the tryptophan side chain was dominant. By contrast, EID and CAD of the corresponding singly deprotonated species (Table S5A for H-GNLWATGHFM$\mathrm{NH}_{2}$ and Table S6A for the peptide pEVNFSPGWGT-NH both in Supplemental Data) produced more informative spectra, allowing structural information to be derived although Trp side chain loss was also present for the peptide H-GNLWATGHFM-NH ${ }_{2}$.

\section{EID and CAD of Singly Deprotonated Peptides with a C-terminal Carboxylic Site but No Acidic Residues}

Because most natural peptides are not C-terminally amidated, we proceeded to characterize the EID behavior of peptides with a carboxylate C-terminus but no other acidic sites. EID and CAD spectra of singly deprotonated bradykinin, H-PPGFSPFR-OH, are shown in Figure $3 \mathrm{a}$ and $\mathrm{b}$, respectively. Complete lists of observed product ions are
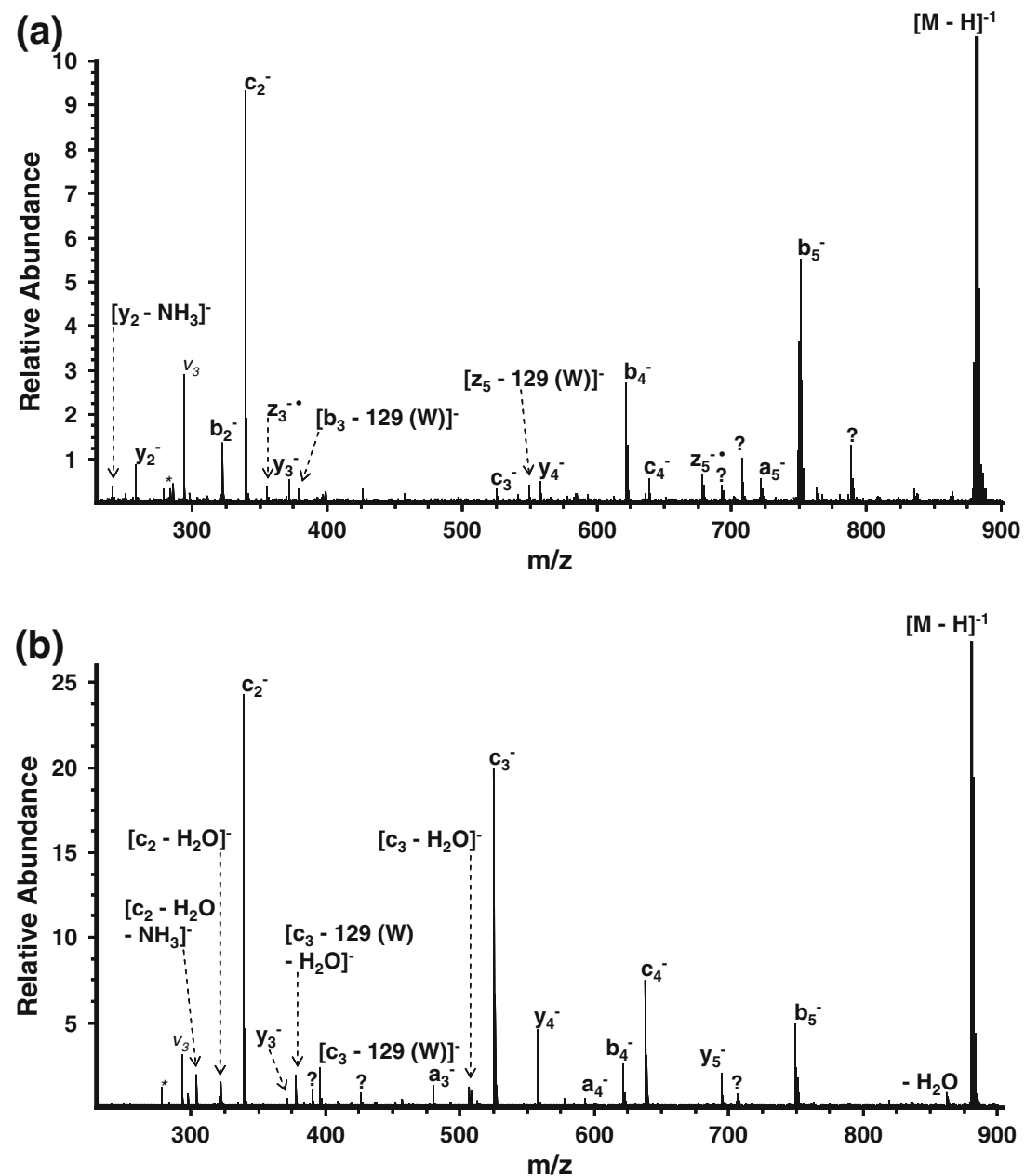

Figure 4. EID (a) and CAD (b) spectra of the singly deprotonated peptide H-WHWLQL-OH. EID and CAD show similar fragmentation patterns; however, EID resulted in the formation of more backbone product ions. Several product ions are unique to EID or CAD, respectively. Product ions corresponding to tryptophan side chain loss are detected in both spectra. ?= unidentified product ions, $v_{3}=3^{\text {rd }}$ harmonic, $*=$ noise peak 
included in Supplemental Data, Tables S8A and S8B. The observed fragmentation behavior for singly deprotonated bradykinin was similar to that of the peptide pEVNFSPGWGT-NH $\mathrm{N}_{2}$ (see previous section), for which EID resulted in more extensive fragmentation compared with CAD. Several product ions from backbone bond cleavage, including $y_{2}, x_{2}, y_{3}, y_{4}, b_{4},\left[z_{4}-30\right], z_{6}^{*},\left[c_{6}-\right.$ 30], $\left[y_{6}-30\right],\left[y_{7}-\mathrm{H}\right]^{\circ},\left[c_{7}-30\right]$, and $a_{7}$ were detected in EID but absent in CAD. Therefore, for bradykinin, EID was more informative than CAD. CAD resulted in the formation of only two backbone product ions, $b_{7}$ and $\left[y_{6}-30\right]$, which were also formed in EID. The $y_{3}$ product ion, corresponding to cleavage on the N-terminal side of proline was detected as both $y_{3}$ and $\left[y_{3}-2 \mathrm{H}\right]$, as observed in EID of Substance P. The increased backbone fragmentation observed in EID compared with CAD may be attributed to differences in ion internal energy following activation. The higher energy in EID allows population of higher vibrational levels and possibly electronic excitation.

EID (Figure 4a and Supplemental Data, Table S9A) of the peptide H-WHWLQL-OH showed similar fragmentation to that observed in CAD (Figure $4 \mathrm{~b}$ and Supplemental Data, Table S9B), including formation of $c-, y$-, and $b$-type product ions. However, some product ions detected in EID were not observed in CAD. These include mainly evenelectron species; $y_{2}, b_{2},\left[b_{3}-129\right],\left[\mathrm{z}_{5}-129\right]$, and $a_{5}$. Two odd-electron species, $z_{3}{ }^{\circ}$ and $z_{5}{ }^{\circ}$, are also unique to EID. On the other hand, the product ions $a_{3}, a_{4}$, and $y_{5}$, are unique to CAD. Similar to other tryptophan-containing peptides, loss of the Trp side chain was observed in both EID and CAD. Product ions formed in EID exhibited less neutral losses compared with CAD, resulting in a less complex spectrum. For example, in CAD, the product ions $c_{3}$ and $c_{4}$ exhibited multiple neutral losses whereas these product ions did not show any neutral losses in EID. We have also previously examined EDD of the peptide H-WHWLQL-OH [65]. We observed that similar to the peptides pEVNFSPGWGT-NH ${ }_{2}$ and H-GNLWATGHFM-NH $\mathrm{N}_{2}$, loss of the tryptophan side chain dominated the EDD spectrum. In contrast, EID (Figure 4a, and Table S9A) and CAD (Figure 4b, and Table S9B) of this peptide provided more extensive fragmentation, as was observed for the peptides $\mathrm{H}$ -
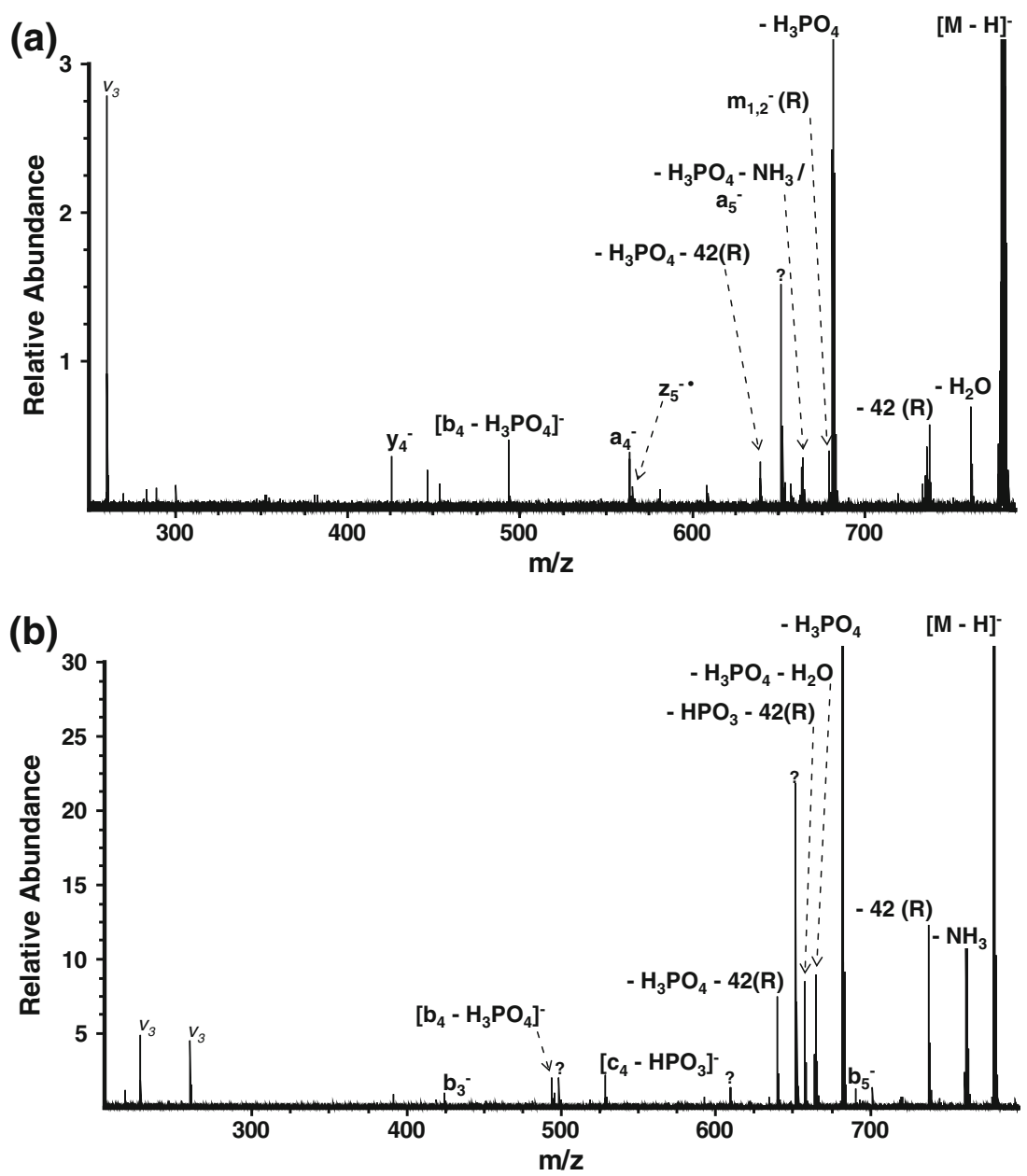

Figure 5. EID (a) and CAD (b) spectra of the singly deprotonated serine-phosphorylated peptide $\mathrm{CH}_{3} \mathrm{CO}-\mathrm{RRA}(\mathrm{pS}) \mathrm{VA}-\mathrm{OH}$. The majority of product ions from EID retained the labile phosphate group, allowing its localization. By contrast, in CAD, all product ions exhibited loss of the phosphate group. ? = unidentified product ions, $v_{3}=3^{\text {rd }}$ harmonic 
GNLWATGHFM-NH $\mathrm{NH}_{2}$ (Tables $\mathrm{S} 5 \mathrm{~A}$ and 5.S5B) and pEVNFSPGWGT-NH 2 (Tables S6A and S6B)

\section{EID and CAD of Singly Deprotonated Cholecystokinin}

Cholecystokinin, H-DYMGWMDF- $\mathrm{NH}_{2}$, which is C-terminally amidated but has two acidic residues, was also examined in our previous EDD experiments [65]. EDD of this doubly deprotonated peptide resulted solely in the formation of the charge-reduced species and $\mathrm{CO}_{2}$ loss from this species. No backbone product ions were detected in EDD. By contrast, EID (Supplemental Data, Table S10A) and CAD (Supplemental Data, Table S10B) of the singly deprotonated species produced more informative spectra, allowing structural information to be derived. For this peptide, Trp side chain loss was absent in EID and CAD spectra, similar to the results obtained with EDD [65].

EID of singly deprotonated cholecystokinin resulted in the formation of several backbone product ions, $a_{5}, y_{5}, a_{6}$, and $\mathrm{z}_{7}$, which were not observed following CAD of the same species. All backbone product ions formed in CAD were also present in the EID spectrum; therefore CAD did not produce any additional structural information for this peptide.

\section{EID and CAD of Singly Deprotonated Modified Peptides}

Lastly, two modified peptides were examined with EID: the first peptide, $\mathrm{CH}_{3} \mathrm{CO}-\mathrm{RRA}(\mathrm{pS}) \mathrm{VA}-\mathrm{OH}$, contains a phosphorylated serine residue and the second peptide, $\mathrm{H}-$ DY*MGWMDF- $\mathrm{NH}_{2}$, contains a sulfonated tyrosine residue. Both these modifications are acidic and, therefore, may benefit from negative ion mode analysis. In EID of the singly deprotonated Ser4-phosphorylated peptide, a major product ion corresponding to neutral phosphoric acid $\left(\mathrm{H}_{3} \mathrm{PO} 4\right)$ loss from the precursor ions is observed (Figure $5 \mathrm{a}$ ), in agreement with the results obtained in CAD (Figure 5b). All assigned product ions are displayed in Supplemental Data, Tables S11A and S11B. However, in EID, the majority of backbone product ions, $y_{4}, a_{4}, z_{5}$, and $a_{5}$,
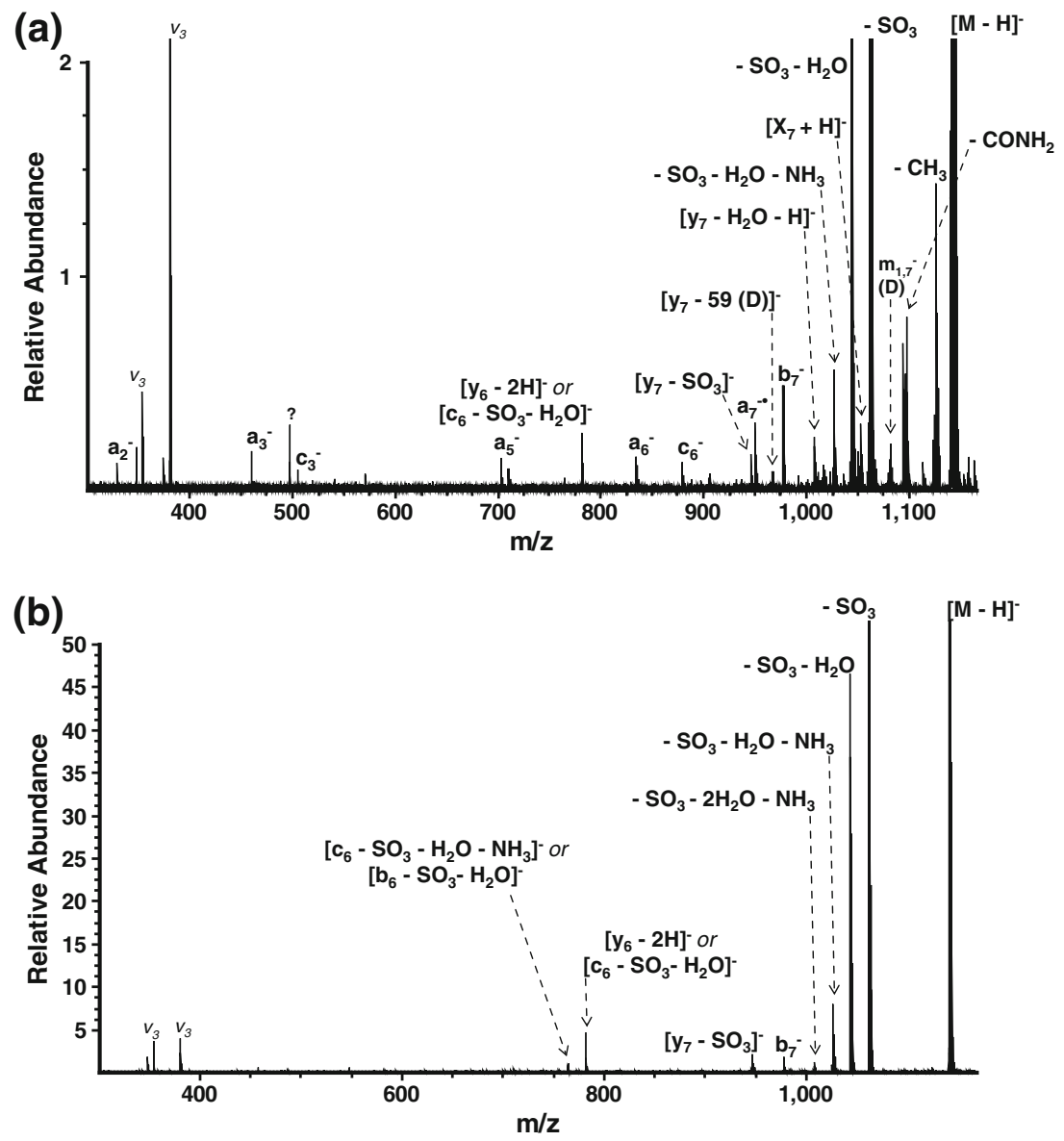

Figure 6. EID (a) and CAD (b) spectra of the singly deprotonated tyrosine-sulfonated peptide cholecystokinin, HDY*MGWMDF-NH $\mathrm{N}_{2}$. EID produced $b, y, c$, and mainly $a$-type product ions that retained the sulfonate group, allowing its localization. By contrast, CAD resulted in sulfonate loss from all, but one, product ions. For complete lists of all generated

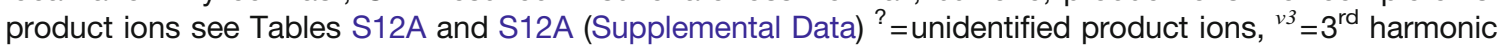


retained the labile phosphate group, allowing localization of the phosphorylation site. Retention of phosphorylation has been previously reported for multiply charged protonated precursor ions in ECD [37, 66-68] and ETD [31], and it was demonstrated that these electron-based reactions can be successfully applied for localization of phosphorylation sites. In sharp contrast, following negative ion CAD, only one product ion, $b_{5}$, retained the phosphorylation.

Similar results were observed for the Tyr2-sulfonated peptide (complete lists of all assigned product ions are provided in Supplemental Data, Tables S12A and S12B). Facile $\mathrm{SO}_{3}$ loss is observed from the precursor ions following EID (Figure 6a) and CAD (Figure 6b). However, in EID, almost all backbone product ions containing the sulfonated tyrosine residue retained the labile sulfonate group, analogous to the behavior of the phosphorylated peptide discussed above. Only one backbone product ion, $y_{7}$, displayed loss of the sulfonate moiety, and the $c_{6}$ product ion was detected as both a sulfonated and non-sulfonated species. These results are similar to those observed in EDD of a Tyr-sulfonated peptide, in which a mixture of sulfonated and non-sulfonated products was observed [35]. Following $\mathrm{CAD}, \mathrm{SO}_{3}$ loss from both the precursor and product ions dominated the spectrum. All, but one, product ions containing the sulfonated tyrosine residue lost the modification. Furthermore, for this peptide EID resulted in more extensive fragmentation compared with CAD. A series of $a$-type product ions, $a_{2}, a_{3}, a_{5}, a_{6}$, and $a_{7}$, was observed for this peptide. These $a$-type product ions were absent in CAD. The $c_{3}$ and $x_{7}$ product ions were also only present following EID.

\section{Conclusions}

EID of singly-charged peptide anions was examined and compared with CAD of the same species. A wide range of product ions, including $b$-, y-, $a$-, $c$-, and some $x$ - and $z$-type product ions, was detected in both EID and CAD, and some product ions were common to both fragmentation techniques. However, unique product ions, observed solely in EID or CAD spectra, respectively, were also detected and, in some cases, significant differences were observed between EID and CAD spectra of the same species. The different fragmentation pathways observed between EID and CAD suggest differences in the manner of ion activation in the two techniques. Based on our results, we postulate that EID of singly deprotonated peptides proceeds via both electronic and vibrational excitation. As a result of vibrational excitation, common product ions are observed between EID and CAD spectra, whereas product ions formed following electronic excitation are only detected in EID. Furthermore, the higher ion internal energy in EID can explain the richer fragmentation observed for several of the examined peptides. Freiser and co-workers suggested that ion activation during ion-electron collisions proceed through excitation of electronic modes, whereas CAD proceeds via excitation of vibrational modes [40]. Fragmentation via electronic excitation in EID has also been proposed by Amster and co-workers [53] and O'Hair and co-workers suggested that EID proceeds via both electronic and vibrational excitation. However, as these authors mention, the exact mechanism of EID is likely to be complex [44, 46].

Regardless of the fragmentation mechanism, we show that electron irradiation of singly charged deprotonated peptides results in formation of several unique backbone product ions, not detected following $\mathrm{CAD}$ of the same species and, thus, providing more extensive structural information. Interestingly, for some peptides CAD provided poor fragmentation, whereas EID resulted in very informative spectra. Furthermore, characteristic losses from the precursor ions, corresponding to side chain loss from Phe, Met, Arg, and Trp residues, were present in the majority of EID spectra of peptides containing these amino acid residues. These characteristic amino acid side chain losses were less consistent in CAD spectra. Some uninformative small neutral losses from the precursor and product ions were also observed, but these losses were less pronounced in EID spectra, rendering them less complex compared with CAD. Formation of several radical species was also unique to EID. In EID of a phosphorylated and a sulfonated peptide, abundant neutral loss of $\mathrm{H}_{3} \mathrm{PO}_{4}$ and $\mathrm{SO}_{3}$ was observed from the precursor ions, similar to CAD. However, in EID, the majority of product ions retained the phosphorylation and sulfonation, respectively. Therefore, EID can reveal the presence of phosphorylation, or sulfonation, and also identify their location.

The results presented here demonstrate that EID is a useful fragmentation technique for the analysis of singly deprotonated peptides, as it provides extensive sequence information, and also shows that EID can provide complementary structural information to that observed in negative ion mode CAD.

\section{Acknowledgments}

This work was supported by an NSF Career Award (CHE05-47699 to $\mathrm{KH}$ ) and a Rackham One-Term Dissertation Fellowship (to AK).

\section{References}

1. Fenn, J.B., Mann, M., Meng, C.K., Wong, S.F., Whitehouse, C.M.: Electrospray Ionization for Mass-Spectrometry of Large Biomolecules. Science 246, 64-71 (1989)

2. Hillenkamp, F., Karas, M., Beavis, R.C., Chait, B.T.: Matrix-Assisted Laser Desorption Ionization Mass-Spectrometry of Biopolymers. Anal. Chem. 63, A1193-A1202 (1991)

3. Tanaka, K., Waki, H., Ido, Y., Akita, S., Yoshida, Y., Yoshida, T., Matsuo, T.: Protein and polymer analyses up to $m / z 100000$ by laser ionization time-of-flight mass spectrometry. Rapid Commun. Mass Spectrom. 2, 151-153 (1988)

4. Dongre, A.R., Jones, J.L., Somogyi, A., Wysocki, V.H.: Influence of peptide composition, gas-phase basicity, and chemical modification on fragmentation efficiency: Evidence for the mobile proton model. J. Am. Chem. Soc. 118, 8365-8374 (1996)

5. Fukui, K., Naito, Y., Akiyama, Y., Takahashi, K.: Charge-state selective fragmentation analysis for protonated peptides in infrared multiphoton dissociation. Int. J. Mass Spectrom. 235, 25-32 (2004) 
6. Paizs, P., Suhai, S.: Fragmentation pathways of protonated peptides. Mass Spectrom. Rev. 24, 508-548 (2005)

7. Wattenberg, A., Organ, A.J., Schneider, K., Tyldesley, R., Bordoli, R., Bateman, R.H.: Sequence dependent fragmentation of peptides generated by MALDI quadrupole time-of-flight (MALDI Q-TOF) mass spectrometry and its implications for protein identification. J. Am. Soc. Mass Spectrom. 13, 772-783 (2002)

8. Cox, K.A., Gaskell, S.J., Morris, M., Whiting, A.: Role of the site of protonation in the low-energy decompositions of gas-phase peptide ions. J. Am. Soc. Mass Spectrom. 7, 522-531 (1996)

9. Dodds, E.D., German, J.B., Lebrilla, C.B.: Enabling MALDI-FTICRMS/MS for high-performance proteomics through combination of infrared and collisional activation. Anal. Chem. 79, 9547-9556 (2007)

10. Dodds, E.D., Hagerman, P.J., Lebrilla, C.B.: Fragmentation of singly protonated peptides via a combination of infrared and collisional activation. Anal. Chem. 78, 8506-8511 (2006)

11. Qin, J., Chait, B.T.: Collision-induced dissociation of singly charged peptide ions in a matrix-assisted laser desorption ionization ion trap mass spectrometer. Int. J. Mass Spectrom. 191, 313-320 (1999)

12. Wysocki, V.H., Tsaprailis, G., Smith, L.L., Breci, L.A.: Special feature: Commentary - Mobile and localized protons: a framework for understanding peptide dissociation. J. Mass Spectrom. 35, 1399-1406 (2000)

13. Cui, W.D., Thompson, M.S., Reilly, J.P.: Pathways of peptide ion fragmentation induced by vacuum ultraviolet light. J. Am. Soc. Mass Spectrom. 16, 1384-1398 (2005)

14. Thompson, M.S., Cui, W.D., Reilly, J.P.: Fragmentation of singly charged peptide ions by photodissociation at $\lambda=157 \mathrm{~nm}$. Angew. Chem. Int. Ed. 43, 4791-4794 (2004)

15. Barbacci, D.C., Russell, D.H.: Sequence and side-chain specific photofragment $(193 \mathrm{~nm})$ ions from protonated Substance P by matrixassisted laser desorption ionization time-of-flight mass spectrometry. $J$. Am. Soc. Mass Spectrom. 10, 1038-1040 (1999)

16. Choi, K.M., Yoon, S.H., Sun, M.L., Oh, J.Y., Moon, J.H., Kim, M.S.: Characteristics of photodissociation at $193 \mathrm{~nm}$ of singly protonated peptides generated by matrix-assisted laser desorption ionization (MALDI). J. Am. Soc. Mass Spectrom. 17, 1643-1653 (2006)

17. Moon, J.H., Yoon, S.H., Kim, M.S.: Photodissociation of singly protonated peptides at $193 \mathrm{~nm}$ investigated with tandem time-of-flight mass spectrometry. Rapid Commun. Mass Spectrom. 19, 3248-3252 (2005)

18. Morgan, J.W., Hettick, J.M., Russell, D.H.: Peptide sequencing by MALDI 193-nm photodissociation TOF MS. Biol. Mass Spectrom. 402, 186-209 (2005)

19. Moon, J.H., Shin, Y.S., Cha, H.J., Kim, M.S.: Photo dissociation at $193 \mathrm{~nm}$ of some singly protonated peptides and proteins with $\mathrm{m} / \mathrm{z} 2000$ 9000 using a tandem time-of-flight mass spectrometer equipped with a second source for delayed extraction/post-acceleration of product ions. Rapid Commun. Mass Spectrom. 21, 359-368 (2007)

20. Morgan, J.W., Russell, D.H.: Comparative studies of 193-nm photodissociation and TOF-TOFMS analysis of bradykinin analogues: The effects of charge site(s) and fragmentation timescales. J. Am. Soc. Mass Spectrom. 17, 721-729 (2006)

21. Ewing, N.P., Cassady, C.J.: Dissociation of multiply charged negative ions for hirudin (54-65), fibrinopeptide B, and insulin A (oxidized). $J$. Am. Soc. Mass Spectrom. 12, 105-116 (2001)

22. Jai-nhuknan, J., Cassady, C.J.: Negative ion postsource decay time-offlight mass spectrometry of peptides containing acidic amino acid residues. Anal. Chem. 70, 5122-5128 (1998)

23. Vinh, J., Loyaux, D., Redeker, V., Bossier, J.: Sequencing branched peptides with CID/PSD MALDI-TOF in the low picomole range: Application to the structural study of the posttranslational polyglycylation of tubulin. Anal. Chem. 69, 3979-3985 (1997)

24. Clipston, N.L., Jai-nhuknan, J., Cassady, C.J.: A comparison of negative and positive ion time-of-flight post-source decay mass spectrometry for peptides containing basic residues. Int. J. Mass Spectrom. 222, 363-381 (2003)

25. Yagami, T., Kitagawa, K., Futaki, S.: Liquid Secondary-Ion MassSpectrometry of Peptides Containing Multiple Tyrosine-O-Sulfates. Rapid Commun. Mass Spectrom. 9, 1335-1341 (1995)

26. Janek, K., Wenschuh, H., Bienert, M., Krause, E.: Phosphopeptide analysis by positive and negative ion matrix-assisted laser desorption/ ionization mass spectrometry. Rapid Commun. Mass Spectrom. 15, 1593-1599 (2001)

27. Bowie, J.H., Brinkworth, C.S., Dua, S.: Collision-induced fragmentations of the $(\mathrm{M}-\mathrm{H})(-)$ parent anions of underivatized peptides: An aid to structure determination and some unusual negative ion cleavages. Mass Spectrom. Rev. 21, 87-107 (2002)

28. Steinborner, S.T., Bowie, J.H.: A comparison of the positive- and negative-ion mass spectra of bio-active peptides from the dorsal secretion of the Australian red tree frog. Litoria rubella. Rapid Commun. Mass Spectrom. 10, 1243-1247 (1996)

29. Harrison, A.G.: Sequence-specific fragmentation of deprotonated peptides containing $\mathrm{H}$ or alkyl side chains. J. Am. Soc. Mass Spectrom. 12, 1-13 (2001)

30. Zubarev, R.A., Kelleher, N.L., McLafferty, F.W.: Electron capture dissociation of multiply charged protein cations. A nonergodic process. J. Am. Chem. Soc. 120, 3265-3266 (1998)

31. Syka, J.E.P., Coon, J.J., Schroeder, M.J., Shabanowitz, J., Hunt, D.F.: Peptide and protein sequence analysis by electron transfer dissociation mass spectrometry. Proc. Natl. Acad. Sci. U.S.A. 101, 9528-9533 (2004)

32. Cooper, H.J., Hakansson, K., Marshall, A.G.: The role of electron capture dissociation in biomolecular analysis. Mass Spectrom. Rev. 24, 201-222 (2005)

33. Mikesh, L.M., Ueberheide, B., Chi, A., Coon, J.J., Syka, J.E.P., Shabanowitz, J., Hunt, D.F.: The utility of ETD mass spectrometry in proteomic analysis. Biochim. Biophys. Acta 1764, 1811-1822 (2006)

34. Zubarev, R.: Protein primary structure using orthogonal fragmentation techniques in Fourier transform mass spectrometry. Expert Rev. Proteomics 3, 251-261 (2006)

35. Budnik, B.A., Haselmann, K.F., Zubarev, R.A.: Electron detachment dissociation of peptide di-anions: an electron-hole recombination phenomenon. Chem. Phys. Lett. 342, 299-302 (2001)

36. Kjeldsen, F., Silivra, O.A., Ivonin, I.A., Haselmann, K.F., Gorshkov, M., Zubarev, R.A.: C- $\mapsto-\mathrm{C}$ backbone fragmentation dominates in electron detachment dissociation of gas-phase polypeptide polyanions. Chem. Eur. J. 11, 1803-1812 (2005)

37. Kweon, H.K., Hakansson, K.: Metal oxide-based enrichment combined with gas-phase ion-electron reactions for improved mass spectrometric characterization of protein phosphorylation. J. Proteome. Res. 7, 749755 (2008)

38. Huzarska, M., Ugalde, I., Kaplan, D.A., Hartmer, R., Easterling, M.L., Polfer, N.C.: Negative Electron Transfer Dissociation of Deprotonated Phosphopeptide Anions: Choice of Radical Cation Reagent and Competition between Electron and Proton Transfer. Anal. Chem. 82, 2873-2878 (2010)

39. Coon, J.J., Shabanowitz, J., Hunt, D.F., Syka, J.E.P.: Electron transfer dissociation of peptide anions. J. Am. Soc. Mass Spectrom. 16, 880-882 (2005)

40. Gord, J.R., Horning, S.R., Wood, J.M., Cooks, R.G., Freiser, B.S.: Energy Deposition During Electron-Induced Dissociation. J. Am. Soc. Mass Spectrom. 4, 145-151 (1993)

41. Cody, R.B., Freiser, B.S.: Electron-Impact Excitation of Ions in FourierTransform Mass-Spectrometry. Anal. Chem. 59, 1054-1056 (1987)

42. Cody, R.B., Freiser, B.S.: Electron-Impact Excitation of Ions from Organics-Alternative to Collision-Induced Dissociation. Anal. Chem. 51, 547-551 (1979)

43. Wang, B.H., McLafferty, F.W.: Electron-Impact Excitation of Ions from Larger Organic-Molecules. Org. Mass Spectrom. 25, 554-556 (1990)

44. Lioe, H., O'Hair, R.A.J.: Comparison of collision-induced dissociation and electron-induced dissociation of singly protonated aromatic amino acids, cystine and related simple peptides using a hybrid linear ion trap-FT-ICR mass spectrometer. Anal. Bioanal. Chem. 389, 1429-1437 (2007)

45. Ly, T., Yin, S., Loo, J.A., Julian, R.R.: Electron-Induced Dissociation of Protonated Peptides Yields Backbone Fragmentation Consistent with a Hydrogen-Deficient Radical. Rapid Commun. Mass Spectrom. 23, 2099-2101 (2009)

46. Feketeova, L., Khairallah, G.N., Hair, R.A.J.: Letter: Intercluster chemistry of protonated and sodiated betaine dimers upon collision induced dissociation dissociation. Eur. J. Mass Spectrom. 14, 107-110 (2008)

47. Budnik, B.A., Haselmann, K.F., Elkin, Y.N., Gorbach, V.I., Zubarev, R.A.: Applications of electron-ion dissociation reactions for analysis of polycationic chitooligosaccharides in Fourier transform mass spectrometry. Anal. Chem. 75, 5994-6001 (2003)

48. Kaczorowska, M.A., Cooper, H.J.: Electron Induced Dissociation: A Mass Spectrometry Technique for the Structural Analysis of Trinuclear Oxo-Centred Carboxylate-Bridged Iron Complexes. J. Am. Soc. Mass Spectrom. 21, 1398-1403 (2010) 
49. Kaczorowska, M.A., Cooper, H.J.: Electron induced dissociation (EID) tandem mass spectrometry of octaethylporphyrin and its iron(III) complex. Chem. Commun. 47, 418-420 (2011)

50. Mosely, J.A., Smith, M.J.P., Prakash, A.S., Sims, M., Bristow, A.W.T.: Electron-Induced Dissociation of Singly Charged Organic Cations as a Tool for Structural Characterization of Pharmaceutical Type Molecules. Anal. Chem. 83, 4068-4075 (2011)

51. Fung, Y.M.E., Adams, C.M., Zubarev, R.A.: Electron Ionization Dissociation of Singly and Multiply Charged Peptides. J. Am. Chem. Soc. 131, 9977-9985 (2009)

52. Yoo, H.J., Liu, H.C., Hakansson, K.: Infrared multiphoton dissociation and electron-induced dissociation as alternative MS/MS strategies for metabolite identification. Anal. Chem. 79, 7858-7866 (2007)

53. Wolff, J.J., Laremore, T.N., Aslam, H., Linhardt, R.J., Amster, I.J. Electron-Induced Dissociation of Glycosaminoglycan Tetrasaccharides. J. Am. Soc. Mass Spectrom. 19, 1449-1458 (2008)

54. Feketeova, L., Khairallah, G.N., Brunet, C., Lemoine, J., Antoine, R., Dugourd, P., O'Hair, R.A.J.: Fragmentation of the tryptophan cluster $[\operatorname{Trp}(9)-2 \mathrm{H}](2-)$ induced by different activation methods. Rapid Commun. Mass Spectrom. 24, 3255-3260 (2010)

55. Yang, J., Mo, J.J., Adamson, J.T., Hakansson, K.: Characterization of oligodeoxynucleotides by electron detachment dissociation Fourier transform ion cyclotron resonance mass spectrometry. Anal. Chem. 77, 1876-1882 (2005)

56. Senko, M.W., Hendrickson, C.L., Pasa-Tolic, L., Marto, J.A., White, F.M., Guan, S., Marshall, A.G.: Electrospray Ionization FT-ICR Mass Spectrometry at 9.4 Tesla. Rapid Commun. Mass Spectrom. 10, 1824-1828 (1996)

57. Antoine, R., Joly, L., Tabarin, T., Broyer, M., Dugourd, P., Lemoine, J.: Photo-induced formation of radical anion peptides. Electron photodetachment dissociation experiments. Rapid Commun. Mass Spectrom. 21, 265-268 (2007)

58. Waugh, R.J., Bowie, J.H., Gross, M.L.: Collision-Induced Dissociations of Deprotonated Peptides-Dipeptides Containing Methionine or Cysteine. Rapid Commun. Mass Spectrom. 7, 623-625 (1993)

59. Waugh, R.J., Bowie, J.H., Hayes, R.N.: Collision-Induced Dissociations of Deprotonated Peptides-Dipeptides Containing Phenylalanine, Tyro- sine, Histidine and Tryptophan. Int. J. Mass Spectrom. Ion Processes 107, 333-347 (1991)

60. Pu, D., Cassady, C.J.: Negative ion dissociation of peptides containing hydroxyl side chains. Rapid Commun. Mass Spectrom. 22, 91-100 (2008)

61. Tsybin, Y.O., Haselmann, K.F., Emmett, M.R., Hendrickson, C.L., Marshall, A.G.: Charge location directs electron capture dissociation of peptide dications. J. Am. Soc. Mass Spectrom. 17, 17041711 (2006)

62. Reiter, A., Teesch, L.M., Zhao, H., Adams, J.: Gas-Phase Fragmentations of Anionic Complexes of Serine-Containing and ThreonineContaining Peptides. Int. J. Mass Spectrom. Ion Processes 127, 17-26 (1993)

63. Waugh, R.J., Eckersley, M., Bowie, J.H., Hayes, R.N.: CollisionInduced Dissociations of Deprotonated Peptides-Dipeptides Containing Serine or Threonine. Int. J. Mass Spectrom. Ion Processes 98, 135-145 (1990)

64. Haselmann, K.F., Budnik, B.A., Kjeldsen, F., Polfer, N.C., Zubarev, R. A.: Can the (M center dot-X) region in electron capture dissociation provide reliable information on amino acid composition of polypeptides? Eur. J. Mass Spectrom. 8, 461-469 (2002)

65. Kalli, A., Hakansson, K.: Preferential cleavage of S-S and C-S bonds in electron detachment dissociation and infrared multiphoton dissociation of disulfide-linked peptide anions. Int. J. Mass Spectrom. 263, 7181 (2007)

66. Chalmers, M.J., Hakansson, K., Johnson, R., Smith, R., Shen, J.W., Emmett, M.R., Marshall, A.G.: Protein kinase A phosphorylation characterized by tandem Fourier transform ion cyclotron resonance mass spectrometry. Proteomics 4, 970-981 (2004)

67. Shi, S.D.H., Hemling, M.E., Carr, S.A., Horn, D.M., Lindh, I., McLafferty, F.W.: Phosphopeptide/phosphoprotein mapping by electron capture dissociation mass spectrometry. Anal. Chem. 73, 19-22 (2001)

68. Stensballe, A., Jensen, O.N., Olsen, J.V., Haselmann, K.F., Zubarev, R. A.: Electron capture dissociation of singly and multiply phosphorylated peptides. Rapid Commun. Mass Spectrom. 14, 1793-1800 (2000) 